will be compelled to offer them advantages at any rate not inferior to those that they can find much nearer home.

The students of the Middlesex Hospital were addressed by Prof. Clifford Allbutt upon abstractions and facts in medicine. His concluding remarks with regard to the value of research laboratories are significant, the lecturer confessing that mere observation of disease and morbid anatomy have taken us almost as far as these means can do. Morbid processes should be tracked in their earliest dynamic initiation in order that they can be arrested in these stages. The clinical laboratory of a county hospital should be the centre of enlightenment to all the private practitioners of the district.

The space at our command has only permitted us to reproduce a relatively small fraction of the many interesting and instructive addresses that were delivered during the course of last week. It is sincerely to be hoped that teachers and students alike have profited by them, and that their united efforts will result in the addition to the profession of a body of workers who will be in the truest sense medical imperialists, and who, while working to the fullest advantage the store of learning they have inherited, will not rest content with it, but extend in all directions the empire of medical knowledge, even up to the threshold of the temple of truth.

\section{F. W. TUNNICLIFFE.}

\section{A NIGHT WITH THE GREAT PARIS} TELESCOPE.

SINCE the final decision was made some years ago to commemorate the Paris Exhibition of 1900 by the installation of a giant telescope which should surpass in size and power any other then in existence, so many varied and contradictory statements have been quoted in the Press, and even in many scientific journals, that a considerable amount of scepticism has been inherent in the minds of most persons interested in the matter. Much of the inaccuracy is traceable to a rather loose estimate being given of the magnification which it was hoped to employ, it being stated that the moon would be apparently brought so close that any object of I square metre area could be distinguished. By the extreme kindness and courtesy of M. François Deloncle, to whose initiative the entire instrument is due, the writer was enabled, not only to thoroughly examine all parts of it during the day, but also to take part in the practical astronomical use to which it is already being put during every clear night. A general view of the siderostat is shown in Fig. I, and the inclusion of the attendant's figure in the upper balcony will give some idea of its relative size. The masonry foundation is about 5 feet 6 inches high, the extreme height of the curved casting carrying the mechanism at the back being about 34 feet. The circular glass mirror seen between the upright fork in front is 6.5 feet $(2$ metres) in diameter, and about I I. 8 inches ( 30 centimetres) thick, being silvered on the upper exposed side. When not in use a large glass plate is lowered over the silvered surface by a windlass worked from the gallery. As the glass mirror weighs some 3600 kilogrammes, and the iron cell and forked support about 3Ioo kilogrammes, the friction on the pivot allowing rotation would have been too great for accurate driving if some provision had not been made for eliminating it. This has been successfully done by immersing the base of the fork casting in a bath of mercury, contained in the circular part of the front half of the main base plate, thereby relieving the pivots of about 9/10ths of the total weight. The rotation of the mirror in a vertical plane is also facilitated by the counterpoise weights shown at the ends of the levers acting on each extremity of the horizontal axis passing through the centre of the mirror.

At the western side of the siderostat, above the NO. I6I5. VOL. 62 ] handles moving the instrument in right ascension and declination, are two telescopes, which by a system of lenses and mirrors enable the observer to read the divisions on two graduated circles without leaving his position. By his side there is also a standard sidereal clock and a telephone.

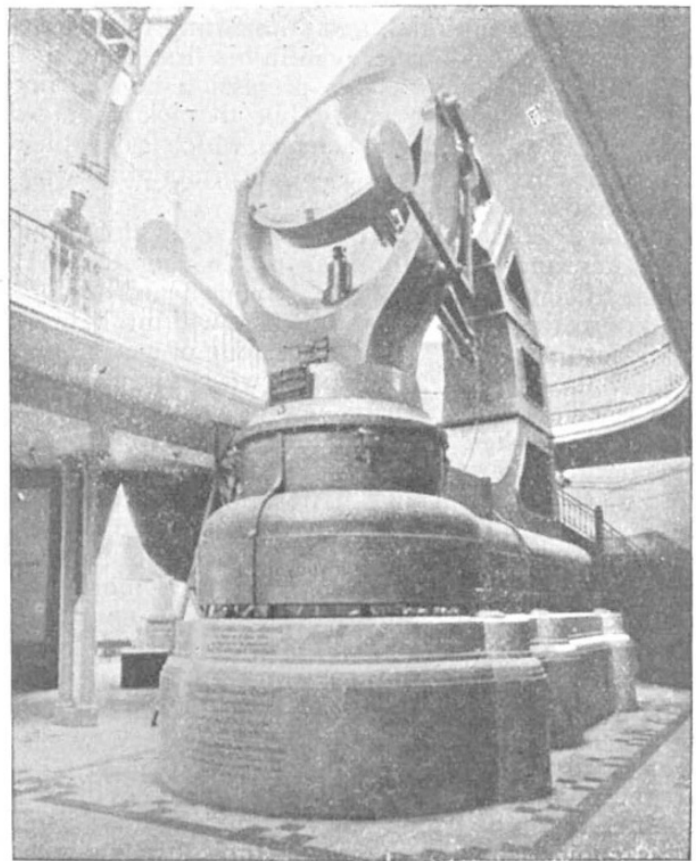

FIG. r.--The great si lerostat, Paris, rgoo.

Leaving now the siderostat, and mounting the staircase seen behind it, access is gained to the upper balcony which runs round both sides of the whole length of the building. Fig. 2 is a view taken from the eye-end of the telescope, 200 feet away to the south, and the siderostat

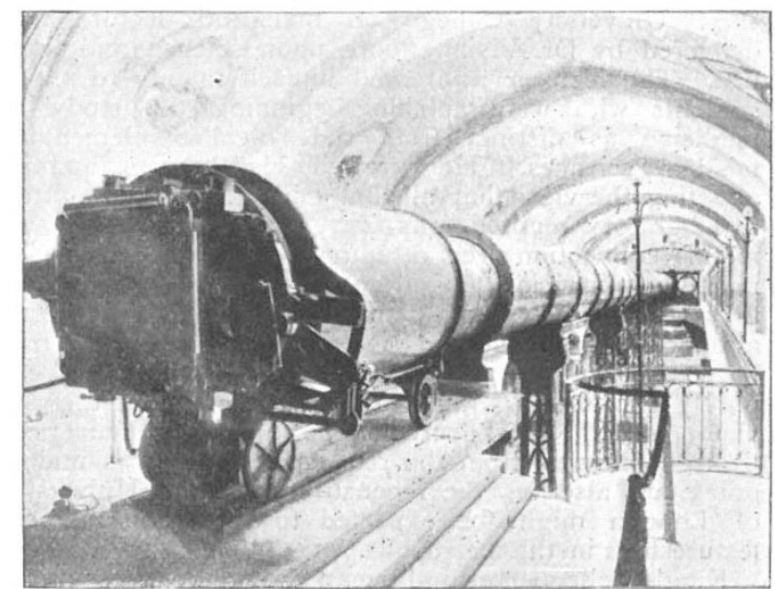

FIG. 2 - Eye-end of the refractor, Paris, Igoo.

can just be seen under the arch at the north end. Above, on the gallery, the circular object-glass is clearly shown in its case. Two of these lenses are to be provided, one specially corrected for visual work, the other for photographic purposes. The lens completed and in position is the latter. The carriages for holding these lenses in 
their massive cells are enclosed in the large rectangular glass case shown in the figure, and being mounted on rails, it is a matter of but a few moments to interchange the position of the lenses with respect to the long tube seen extending from end to end of the gallery. This enormous (and, from an astronomical point of view, probably superfluous) tube is composed of twenty-four sections of sheet steel, each about 8 feet 3 inches $(2.50$ metres) long, and 59 inches ( $1^{\circ} 50$ metres) in diameter, which are supported on six braced columns rising from the floor below.

At the near end of the tube is shown the massive tailpiece, with the various arrangements for focussing, clamping and rotation of the photographic plate. The focussing is done by traversing the whole of the tailpiece on the two short rails, a motion of about 5 feet (I50 metres) being allowed, as it is unlikely that the focal lengths of the two lenses will turn out identical.

The lens in position, corrected for the photographic rays, is $49^{\prime} 2$ inches ( 1.25 metres) aperture, and 187 feet ( 57 metres) focal length. The diameter of the image of the sun or moon at the principal focus will therefore be about $2 \mathrm{I}$ inches in diameter.

Rotation of the photographic plate, about 30 inches square, during exposure is necessary on account of the fact that when a siderostat is used, only the central point of the field of view remains stationary, all the surrounding parts having a motion round this as centre. To eliminate this M. Gautier has provided a subsidiary clock, placed to the rear of the eye-end, which, by means of connecting gear to the milled wheel seen on the circumference of the end of the tube, turns the whole tail-piece of the telescope at any desired rate. For visual observations the plate-holder is removed, and an adapter carrying an eye-piece is inserted. The whole of this eye-end section is now covered in by a temporary dark-room.

To admit the light from celestial objects to the mirror of the siderostat, the roof and walls of the building for some 70 or 80 feet are made in two sections, one of which slides to the north, the other to the south, allowing of a clear view from the zenith southwards to within some few degrees of the horizon. This done (requiring some six or eight attendants to work the pulley blocks), all the subsequent movements and adjustments are easily made by two observers. One is stationed at the base of the siderostat, with the handles for working the instrument, telescopes for reading the circles, sidereal clock and telephone all within his reach. Whatever object is selected from the previously prepared working list for the evening, the declination handle is turned until the scale reading seen through the telescope gives the correct declination of the object. Then the hour-angle, or difference between the sidereal time indicated by the clock and the right ascension of the star, is set by means of another handle and the second small telescope. This done, the required object will be near the centre of the field of the large telescope, and the clock being set running to keep it there, the astronomer takes his place at the eye-end to bring it exactly to the centre of the eye-piece. He also has a telephone by his side, and for a space of some two or three minutes there is a continual rross-fire of such terms as "Déclinaison," "Ascension droit," "Doucement," "Au sens contraire," with various endearing terms of admonition in cases of overdoing the movements. Considering, however, the comparatively high power ( 500 ) which is the lowest used, it is astonishing how quickly an object is obtained after the setting of the circles. This in itself furnishes an incontestable proof of the extremely accurate adjustment of the siderostat and telescope, both as regards the angle of its polar axis and its position in the meridian. The object being found, all lights are extinguished and a drawing or photograph made as carefully as possible. On the evening it was my privilege to be present, our NO. I6I 5 , VOL. 62 ] first object was the Ring Nebula in Lyra (Messier 57) The astronomer in charge was $M$. Eugène Antoniadi, of the Juvisy Observatory, near Paris, who has started a systematic study of nebulæe with the telescope. This view of the nebula surpassed anything seen before, although frequent observations of it have been made by the writer with a telescope of 36 inches aperture. The great increase of light given by the great glass made it possible to use a highly magnified image, which was at the same time bright enough for the eye to detect detail without any strain.

We next turned to the coloured double star $\beta$ Cygni, after that a Lyræ (Vega), the companion of which was a very conspicuous object. During all this time the instrument was being used in a building containing several hundred people, electric lights all over heating the air, and the huge searchlights and illuminations from the surrounding buildings causing considerable atmospheric glare-conditions under which none but first-class apparatus would be workable. However, owing probably in a great measure to the large proportion of the roof which is opened, the star images were not inconveniently unsteady.

M. Deloncle appears indefatigable in doing his utmost to entertain any one having special interest in his protégé. Parties of guests are often there to listen to a short address from him on its construction and installation, after which they go to the eye-piece, and in turn see whatever may be on view. This goes on till after midnight, and then, the last visitor away, all lights are turned out, the lens case opened to permit of air circulation, and about half an hour or more allowed to elapse for the general temperature to be equalised throughout the variousparts. We turned next to an object which M. Antoniadi had not previously observed (a small planetary nebula in Sagitta), found it quite easily by the circles and slight subsequent sweeping, and then occupied about an hour and a half in careful drawing. This nebula is G.C. 4572, and M. Antoniadi's drawing appears in the Bulletin de lot Société Astronomique de France, September 1900.

In sweeping from one object to another, thousands of stars cross the field of view, and it was specially noticeable that no distortion of the star images was to be detected as the mirror was moved to different angles of incidence. With such a high power this is in itself a severe test of the planeness of the silvered surface, and it is worth drawing attention to the fact that the figuring of this mirror by M. Gautier has been done entirely by mechanical means, controlled at every step by the most delicate optical tests.

In connection with the actual work of observing, nothing is so important as accurate clock driving, in order that the astronomer may not be troubled by constantly having to bring the object into the centre of the field. How efficient this instrument is in this respect will be understood when it is stated that during the period for which the clock runs at one winding, about forty-five minutes, the star images do not move sufficiently in the field of a power of 500 to necessitate any adjustment. The angular diameter of the field of view is about 3 of arc.

By the time M. Antoniadi had finished his drawing of this planetary nebula it was about 3.0 a.m., and approaching daylight. The mirror cover was lowered into its place, the two sliding sections of the roof pulled together over the mirror, and the clock stopped. In a few minutes M. Antoniadi and myself were the only occupants of the gallery, and the institution being already in such regular use that a couple of beds are provided for observers staying all night, we decided that, as it was so terribly hot indoors, we would take up our beds and camp out in the courtyard. We did this, and sleep being somewhat out of the question, spent some time gazing upward in the hope of seeing some forerunners of the August 
Perseids, with the usual result of latter-day meteor watching--we saw none. However, it was a novel and exceedingly pleasant experience to be there lying under the stars, the greatest telescope on earth immediately to one's side, the highest building in the world towering over our heads.

It is to be hoped that after the Exhibition is over the telescope will find a resting-place under the Home Government at some station out of the city, where the purity of the atmosphere will allow of its power being efficiently used.

C. P. BUTLER.

\section{TOBACCO.}

W HEN Columbus landed in 1492 in the West Indies he found the natives smoking a herb wrapped in a maize leaf, and the name of the herb was Tobago. In I 560 Jean Nicot distributed plants raised from seed to various parts of Europe. These two events give us the clue to the popular and scientific names of a drug the cultivation and preparation of which have now attained such enormous importance that Governments are sup. ported by the revenue derived from its taxation, and colossal fortunes are made by its sale. Some idea of the scale on which the industry is carried on may be gathered from the statistics recently published in the "Year-book of the United States Department of Agriculture for I 899, , where we read that during that year $266,661,752$ pounds of tobacco, $4,542,016,570$ cigars and $4,590,388,430$ cigarettes were prepared in the United States alone, yielding a revenue to the Government of $52,043,859^{\circ} 05$ dollars.

Small wonder then that the cultivators of so valuable a plant have shown great interest in all the processes of raising, planting, manuring and gathering the crop, and of drying, curing and preparing it for market ; or that consternation has arisen in their midst at the origin and spread of a disease which attacks the golden leaf, and bids fair to ruin the crop in some districts. It happens, moreover, that biological problems of wide significance are arising in connection with the complex art of fermenting the leaf so as to obtain the best flavour and strength, as well as in regard to the "Mosaic disease" above referred to, and the experience of Dutch growers, of which an excellent account is now to band in Koning's "Der Tabak, Studien ueber seine Kultur und Biologie" (Amsterdam and Leipzig: W. Engelmann, I900), shows that the employment of scientifically trained botanists in the technical laboratories of tobacco plantations is likely to be as usual an event in the future as in breweries and bacteriological laboratories.

The tobacco plant is exceedingly small in the seedling stage-eighteen thimblefuls of seed suffice for a hectare, i.e. two and a half acres of land-and is very carefully raised in pots and manured with pigeon's dung, planted out and weeded with extraordinary precautions against numerous enemies, and the leaves eventually picked by hand, sorted, tied into bundles and hung to dry. It is a very exhausting crop, and requires much potash; and an astonishing amount of information has accumulated concerning the effects of different soils, manures, climate and other factors of the environment on the properties of the leaves. Moreover, there are numerous cultivated races in existence in the various tobacco-growing countries, as always occurs with planted crops.

During the process of slow drying the leaf may remain alive for two to three weeks, and the contained starch is converted into sugar, and further alterations result in an increase of acids. Proteids diminish and amines increase, but the nitrates and alkaloids (nicotin) should undergo no change. The slow alterations referred to are essential, and due to enzyme and other actions in the still living leaf; in artificially or rapidly dried leaves the arrest of such changes materially affect the flavour and burning of the tobacco, and naturally much turns on the age and quality of the leaf itself, the soil and season and other conditions of growth, \&c.

The dried or "cured" leaves are next submitted to fermentation, a process of vital importance in the opinion of the tobacco expert, since it is this which determines the finer flavours and odours of the manufactured product. Fermentation is started by damping heaps of I 5,000 to 30,000 lbs. of the dried leaves, packed in a special manner, and carefully watched by experienced workmen as the temperature rises. The process occupies three to four months, and the leaves are turned about once a month. The temperature rises to about $50-56^{\circ} \mathrm{C}$., and a loss of vapour, accompanied by a sweet and sharp odour, is noticed. The reaction may be neutral, though in some cases ammonia is given off, due to the action of undesired bacteria.

As would be expected, the fermentation is always accompanied by bacteria; but it has long been in dis pute whether the essentials of the process are due to bacteria or to the action of special enzymes in the cells of the leaves.

Suchsland's researches had convinced him, not only that the fermentation is due to bacteria, but that a peculiar species of bacteria was specially concerned in the production of the approved flavour, and that the desirable properties of Cuban tobaccos could be imparted to inferior growths by introducing this species into the fermentation. Loew, on the other hand, maintained that the aroma and flavour depend simply on the action of enzymes or other cell-contents in the leaf itself.

Koning has investigated the various bacteria found in the fermenting heaps, and followed the changes induced in the tobacco.

Put generally, the fermented tobacco undergoes little or no change as regards the total nitrogen or the nicotin, but organic acids diminish, and the sugars and nitrates are destroyed, and various aromatic substances are formed which affect the quality of the product.

Among the bacteria isolated Koning claims to have found the species concerned in this remarkable neutral fermentation, and which imparts the aroma and flavour desired, and thus confirms Suchsland's results. He states that tobacco infected with the specific bacteria, fermented and made up, and then handed to experts, was selected by the latter as the superior from specimens containing other kinds. There is more than a touch of the dramatic in this scene of the experts sitting down to smoke a pair of cigars each, in packets of two, and labelled $a$ and $b, c$ and $d, \& c$., only; but the evidence appears conclusive.

During the last ten years increased attention has been drawn to a disease of tobacco leaves, which causes irregularly alternating light and dark patches, and is known as the "Mosaic disease." Koning has established that this is infectious, and is carried through the fields by the fingers of the workmen who "top" the growing plants by pinching off the buds. He has examined the various fungi known to cause leaf-diseases in tobacco, and cannot refer it to these, and the presumption that it is a bacterial disease was strengthened by finding that certain manured soils were almost sure to have badly diseased plants on them ; and that experiments showed that if a bit of diseased leaf, or a little of the sap from such is rubbed into a wound, the young leaves formed above the wound contract the disease. The same result follows if such sap is placed at the roots of healthy plants. But infection fails in all these cases if the sap is previously boiled.

Here may be mentioned that Adolf Mayer had proved the infectious nature of the filtered sap in 1885, and Beijerinck, working at this disease a short time ago (1898), had come to the conclusion that since no

NO. 1615 , VOL. 62$]$ 